\title{
A POLÍTICA BRASILEIRA DE PREVENÇÃO DA SÍNDROME DA IMUNODEFICIÊNCIA ADQUIRIDA NA ESCOLA (1994-2014) E O PAPEL DA ORGANIZAÇÃO DAS NAÇÕES UNIDAS PARA A EDUCAÇÃO, A CIÊNCIA E A CULTURA*
}

\author{
Mariana Braga Neves ${ }^{1}$ \\ Luiz CARlos Romero ${ }^{2}$
}

\begin{abstract}
RESUMO: O artigo analisa a evolução da política de prevenção da síndrome da imunodeficiência adquirida (AIDS) dirigida a adolescentes e jovens, e desenvolvida nas escolas, no Brasil, no período de 1994 a 2014, bem como o papel da Organização das Naçóes Unidas para a Educação, a Ciência e a Cultura (UNESCO). Utiliza análise documental e entrevistas com gestores e técnicos das áreas de saúde e educação e stakeholders. Descreve a evolução da política e a natureza dos programas implementados quanto à cobertura, à qualidade e à efetividade das açóes, aos resultados e ao papel das instituiçóes envolvidas. Observou-se ampliação de cobertura e baixa efetividade das açóes desenvolvidas, dificuldades da integração interinstitucional e barreiras para a execuçáo da política. Discutem-se a sustentabilidade e as alternativas à revisão da política.
\end{abstract}

Palavras-chave: Aids. Educação em saúde. Educação sexual. Prevenção de doenças.

\section{ACQUIRED IMMUNODEFICIENCY SYNDROME PREVENTION POLICY AT SCHOOL IN BRAZIL (1994-2014) AND THE ROLE OF UNITED Nations EduCaTional, SCIENTIFIC AND Cultural ORGanization}

ABSTRACT:The paper analyzes the evolution of acquired immunodeficiency syndrome (AIDS) prevention policy aimed at adolescents and young people, and developed in schools, in Brazil, in 1994-2014, as well as the role of United Nations Educational, Scientific and Cultural Organization (UNESCO), from documentary analysis and interviews with stakeholders. It describes the politics evolution and the nature of different programs implemented, concerning coverage, quality and effectiveness of the actions, results and the

\footnotetext{
*O presente artigo é resultante do projeto de pesquisa "Evolução da política de prevenção da síndrome da imunodeficiência adquirida (AIDS) e o papel da Organização das Naçôes Unidas para a Educação, a Ciência e a Cultura (UNESCO)".

${ }^{1}$ Organização das Naçôes Unidas para a Educação, a Ciência e a Cultura (UNESCO). Associação Brasileira de Sexualidade Humana (SBRASH) - São Paulo (SP), Brasil. E-mail: marianabraga73@gmail.com ${ }^{2}$ Diretoria Regional de Brasília da Fundação Oswaldo Cruz (Fiocruz) - Brasília (DF), Brasil. E-mail: romero.luizcarlos@gmail.com DOI: 10.1590/ES0101-73302017166435
} 
role of the institutions involved. Expansion of coverage, low effectiveness of the actions taken, difficulties of inter-institutional integration and barriers to policy implementation were observed. It discusses the sustainability and alternatives to the policy revision.

Keywords: AIDS. Health education. Sex education. Disease prevention.

\section{LA POLITIQUE BRÉSILIENNE DE PRÉVENTION DU SYNDRÔME D'IMMUNODÉFICIENCE ACQUISE À L'ÉCOLE (1944-2014) ET LE RÔLE DE L'ORGANISATION DES NATIONS UNIES POUR L'ÉDUCATION, LA SCIENCE ET LA CULTURE}

RÉSUMÉ: L'article analyse l'évolution de la politique de prévention du syndrome d'immunodéficience acquise (SIDA) développée dans les écoles au Brésil s'adressant aux adolescents et aux jeunes, entre 1994 et 2014, et aussi le rôle de L'Organisation des Nations Unies pour l'éducation, la science et la culture (UNESCO). On a utilisé l'analyse documentaire et des interviews avec les gestionnaires et techniciens de la santé et de l'éducation et les stakeholders. Il décrit l'évolution de la politique et l'essence des programmes exécutés en relation à la dimension, à la qualité et l'efficacité des actes, aux résultats et au rôle des institutions concernées. On a observé l'expansion de la couverture et une faible efficacité des actes développés, les difficultés d'intégration interinstitutionnelles et des barrières à l'exécution de la politique. Ils sont discutés la durabilité et les alternatives à la revue de la politique.

Mots-clés: SIDA. L'éducation à la santé. L'éducation sexuelle. La prévention des maladies.

\section{Introdução}

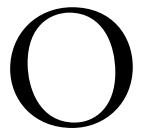

reconhecimento de que a escola é um espaço institucional estratégico para a promoção da saúde e a prevenção das doenças sexualmente transmissíveis (DST) e da síndrome da imunodeficiência adquirida (AIDS) está presente na formulação da política brasileira de enfrentamento da epidemia desde seus primeiros momentos (UNESCO, 2003). Para os seus propositores, a relevância da ação preventiva dirigida a adolescentes e jovens escolarizados decorre do reconhecimento de que "a informação, valores e conhecimentos transmitidos pela escola exercem grande influência na vida desses jovens" (UNES$\mathrm{CO}, 2003$, p. 13) e do fato de a escola e suas redes congregarem uma proporção considerável daquela população, facilitando o seu acesso à instituição.

Vírus da imunodeficiência humana (HIV) e AIDS são "temas especiais" para a Organização das Nações Unidas para a Educação, a Ciência e a Cultu- 
ra (UNESCO). Entre as funções que lhe são atribuídas na divisão de trabalho do Programa Conjunto das Naçôes Unidas sobre o HIV/AIDS (UNAIDS), a UNESCO é a principal organização encarregada da prevenção da infecção pelo HIV entre os jovens nas instituições de ensino (UNESCO, s.d.). No Brasil, a participação da UNESCO é referida como tendo acontecido "desde o primeiro momento do enfrentamento desta situação" e caracterizada como "significativo apoio institucional e cooperação técnica" (UNESCO, 2003, p. 10) ao Ministério da Saúde e a outras agências das Naçóes Unidas. O foco em prevenção, nos jovens e na escola, constitui sua principal contribuição para os resultados alcançados até então (STERN, 2005).

\section{Método}

A pesquisa associou análise documental e entrevistas. A documentação produzida durante a formulação e a implementaçấo dos projetos de cooperação, os quais tem sido mantidos pelo Ministério da Saúde e a UNESCO entre 1994 e 2014, foi recuperada e analisada, objetivando sistematizar, consolidar e analisar a informação técnica e estatística disponível sobre as políticas de prevenção da AIDS dirigidas à escola. Também foram consultados relatórios de estudos de avaliação externa da atividade, realizados sob os auspícios dos Ministérios da Saúde e da Educação assim como da UNESCO.

Com o objetivo de obter evidências de natureza qualitativa que confirmassem, qualificassem e complementassem as informaçôes produzidas pela análise documental, foram realizadas entrevistas com representantes dos Ministérios da Saúde e da Educação, das Secretarias Estaduais e Municipais de Saúde e de Educação, das organizaçôes da sociedade civil (OSCs) e das organizaçôes não governamentais (ONGs), e dos stakeholders, a fim de buscar, na vivência de gestores e executores de açôes do programa de controle e stakeholders, elementos que esclarecessem os resultados identificados sobre cobertura, qualidade, impacto e sustentabilidade das intervençôes; integraçáo interinstitucional; resultados positivos e dificuldades à implementação da política; e o futuro percebido dessa política, além de uma avaliação da contribuição da cooperação técnica entre o governo brasileiro e a UNESCO nesse campo.

O grupo de entrevistados escolhidos constituiu uma amostra de conveniência, selecionada para incluir representantes dos diferentes executores de açóes do programa e stakeholders, em cinco regióes dentre as mais afetadas pela epidemia (Estados de São Paulo e Rio de Janeiro e o Distrito Federal) e as que estão a constituir suas novas fronteiras, em razão da expansão geográfica, do número de casos e do perfil da epidemia (os Estados do Amazonas e do Rio Grande do Sul).

As entrevistas foram realizadas no período de janeiro a abril de 2015. 


\section{Resultados e discussão}

\section{Análise documental}

Atividades de prevenção voltadas para adolescentes e jovens no ambiente escolar começaram a ser desenvolvidas já nos últimos anos da década de 1980, como componentes dos primeiros programas de controle da AIDS implantados no país pelos Estados e municípios das regióes mais afetadas (STERN, 2005). No entanto, a construção e a implementação de uma política de educação em sexualidade na escola, com foco na prevenção do HIV e de abrangência nacional, só se iniciaram em 1994. Desde então, o governo federal, por meio da açáo conjunta dos Ministérios da Saúde e da Educação e com a cooperação da UNESCO, tem "reunido esforços para que os temas de saúde sexual e reprodutiva sejam trabalhados nas escolas" (BRASIL, 2006a, p. 9).

O "Projeto Escolas" foi iniciado em 1994 - por iniciativa dos Ministérios da Saúde e da Educação, para a formação presencial de professores e orientadores pedagógicos, em 16 unidades da Federação mais afetadas pela epidemia de HIV - e grandemente ampliado no ano de 1999, alcançando, até o final do ano 2000, aproximadamente 250 mil professores e mais de 9 milhôes de alunos dos ensinos médio e fundamental, em todo o país (BRASIL, 2006a).

A avaliação desse projeto, realizada em 2001 (RUA; ABRAMOVAY, 2001), evidenciou a necessidade e a urgência dessa intervenção em vista da comprovaçáo da precocidade da iniciaçáo sexual dos adolescentes brasileiros e da elevada proporção de alunos que "apontam formas incorretas de prevenção da AIDS". Além disso, a avaliação demonstrou que, "inequivocamente", o projeto tinha levado a efeito "um amplo e diversificado leque de açóes envolvendo diretores, orientadores educacionais, coordenadores de ensino, professores, pais e alunos", com "efetivo impacto" sobre todos aqueles atores, destacando-se aquele sobre os alunos - em relação aos quais os avaliadores encontraram correlação entre a exposição a atividades de prevenção na escola e o uso do preservativo - e os pais que se disseram mais informados, mais dispostos a conversar sobre sexualidade com seus filhos e com uma atitude mais favorável à distribuição de preservativos na escola (RUA; ABRAMOVAY, 2001, p. 199 e 223-224). A distribuiçâo de preservativos na escola permanecia "um tema polêmico", mas a atitude dos pais a respeito era "afetada [no sentido do favorecimento da distribuição] pela iniciativa da escola de convidar os pais para participarem das atividades de prevenção" (RUA; ABRAMOVAY, 2001, p. 215).

Os principais motivos apontados para o não desenvolvimento de açôes de prevençáo das DST e da AIDS nas escolas eram: a falta de materiais didáticos, a falta de professores capacitados e a não inserção do tema nos projetos político-pedagógicos das instituiçôes de ensino (RUA; ABRAMOVAY, 2001, p. 68-69). 
Outro estudo, realizado em 2.138 municípios nos meses de outubro a dezembro de 2003, pela ONG Associação de Prevenção e Tratamento da AIDS (APTA), a pedido do Ministério da Educação (SOUZA, 2004), evidenciou que o percentual de escolas que mantinham alguma atividade de prevenção das DST e da AIDS havia subido de 19\%, em 1998, para 66\%. Segundo o estudo da APTA, se a cobertura por açóes de prevenção das DST e da AIDS nas escolas tinha aumentado muito, a qualidade das atividades, no entanto, deixava a desejar: na maioria dos casos, elas se restringiam a palestras e seminários desconectados da atividade regular de ensino. Somente 334 municípios mantinham projetos contínuos, com oficinas pedagógicas e formação de educadores. As principais dificuldades apontadas pelos professores eram a falta de material de apoio, de recursos financeiros, de capacitação profissional e de material didático, e, em 8,8\% das escolas estudadas, a resistência dos pais. As Secretarias de Educação, por sua vez, solicitavam fornecimento de material didático, formação e qualificação dos professores e recursos financeiros (SOUZA, 2004).

Outras iniciativas surgiram e ampliaram o olhar sobre a prevenção ao HIV, incluindo os demais temas da educação em sexualidade baseada em Direitos Humanos. Em 2003, por iniciativa da UNESCO, foi desenhado e implementado pelos Ministérios da Educação e da Saúde, com o apoio de agências das Naçóes Unidas no Brasil, o "Projeto Saúde e Prevenção nas Escolas" (SPE), com foco em educação em sexualidade, relaçóes de gênero e prevenção do HIV e de outras DST. O projeto previa a articulação intersetorial (educação-saúde), a organização de grupos gestores intersetoriais, a formação conjunta de profissionais de educação e saúde, e de jovens para atuação entre pares. A ação incluía, também, a elaboração e a distribuição de materiais educativos assim como a disponibilização de preservativos em escolas que trabalhassem com os temas da educação em sexualidade.

Nesse mesmo ano, um novo projeto de cooperação foi firmado entre o Ministério da Saúde e a UNESCO, como uma das estratégias de implementação de uma nova etapa do programa nacional de controle da AIDS (conhecida como Projeto AIDS III), no contexto do qual se reconhecia que o processo de articulação entre os setores da saúde e da educação, iniciado na etapa anterior e grandemente mediado e apoiado pela UNESCO, "precisa[va] ser aprofundado e aperfeiçoado" (UNESCO, 2003 , p. 12). A continuidade da parceria com a UNESCO — por sua atuação e história de relaçóes cooperativas com o setor da educação - era considerada "crucial para o controle da epidemia de AIDS no Brasil como um todo, pela ênfase dada nas questóes de prevenção associadas à educação e comunicação” (UNESCO, 2003, p. 13).

Em 2005, foi assinado um acordo entre os Ministérios da Saúde e da Educação “para implementação do Programa Saúde e Prevenção nas Escolas”, realizadas 47 reunióes/oficinas para gestores e gerentes de saúde e educação dos níveis estadual e municipal, e produzidos 9 materiais instrucionais (BRASIL; UNESCO, 2006b, p. 3). Até 2007, "mais de 90\% das escolas desenvolveram algum tipo de ação com temas relacionados à AIDS", e $9 \%$ das de ensino fundamental e 18\% 
das de ensino médio mantinham programas de distribuição gratuita de preservativos (BRASIL; UNESCO, 2008, p. 5).

O desenvolvimento de atividades voltadas para a prevenção das DST e da AIDS nas escolas, no âmbito da "promoção da saúde sexual e reprodutiva", continuou a acontecer, com a participação dos Ministérios da Saúde e da Educação e a cooperação da UNESCO e, pouco depois, do Fundo das Nações Unidas para a Infância (UNICEF), no âmbito do Projeto SPE, implantado a partir de 2005 (BRASIL, 2006a, p. 9), de tal forma que uma pesquisa que analisou os planos de ações e metas para 2006 dos Estados e municípios incluídos na "Política de Incentivo" encontrou que 51,3\% desses planos contemplavam açóes dirigidas a "jovens em escolas" (GRANGEIRO et al., 2012, p. 959).

Em 2007, o SPE foi incorporado ao Programa Saúde na Escola (PSE), uma política intersetorial de saúde e educação instituída "com a finalidade de contribuir para a formação integral dos estudantes da rede pública de educação básica por meio de ações de prevenção, promoção e atenção à saúde" (BRASIL, 2007). Um conjunto de portarias interministeriais e do Ministério da Saúde instituiu a Comissão Intersetorial de Educação e Saúde na Escola e redefiniu as regras e os critérios para adesão dos Estados, do Distrito Federal e dos municípios ao progra$\mathrm{ma}$, apontando também o respectivo incentivo financeiro para custeio de açóes.

O PSE se organiza em dois grandes componentes: um voltado para a assistência à saúde dos estudantes (avaliação antropométrica; situação vacinal; saúde bucal, ocular e auditiva; desenvolvimento da linguagem; detecção de doenças negligenciadas e em eliminação) e outro para a promoção da saúde e a prevenção de doenças (segurança alimentar e alimentaçáo saudável; cultura de paz e Direitos Humanos; saúde mental; promoçáo da saúde sexual e da saúde reprodutiva; prevenção ao uso de álcool, tabaco, crack e outras drogas). Os temas do primeiro componente - de assistência à saúde dos estudantes - têm tido mais prioridade de parte dos Ministérios da Educação e da Saúde.

A "política pública de educação em sexualidade" - tendo como foco o desempenho do PSE em relação a esse componente - foi objeto de avaliação, realizada no final de 2013, envolvendo 1.627 pessoas, entre gestores estaduais e municipais de sistemas de educação e saúde, gestores de unidades escolares, professores, gestores e técnicos de unidades básicas de saúde (UBSs), pais e alunos, de oito capitais (LOMBARDI, 2014).

Entre os aspectos positivos da implementação da nova política, a avaliação encontrou: a integração da atividade nos projetos político-pedagógicos de todas as redes de ensino pesquisadas; a existência de materiais produzidos para o SPE e sua aprovaçáo por todos os grupos de atores estudados; o modelo de capacitaçáo de professores, considerado satisfatório pela maioria dos gestores; e a aprovação, pelos alunos, das atividades do projeto. 
Os aspectos negativos apontados constituem, na verdade, mais insuficiências do que falhas: ainda que considerada adequada quanto ao "modelo", a capacitaçáo de professores é vista como insatisfatória em quantidade e frequência pelos professores e pelos gestores de redes e de escolas; em toda a parte, os materiais educativos, aprovados por gestores, professores e alunos, estavam disponíveis em quantidade insuficiente; a educação por pares só foi encontrada em uma das capitais, e não foi satisfatória em nenhuma capital; e apenas nas redes de escolas de duas capitais existia disponibilidade permanente de preservativos.

A disponibilizaçáo de preservativos nas unidades escolares - uma das mais importantes mudanças na política, promovidas em meados da década de 2000, objetivando "assegurar que preservativos estejam largamente disponíveis nas escolas e no sistema educacional" (STERN, 2005, p. 49) - continuava sendo uma questão de dissenso entre os pais e as escolas, mas tinha a aprovação total dos alunos. Para o autor da avaliação, a ausência de preservativo coloca em questão o próprio objetivo do SPE, pois todas as açóes realizadas no âmbito da educaçáo em sexualidade perdem o sentido se não houver preservativo disponível (LOMBARDI, 2014).

Ele conclui que as açôes do SPE eram "insuficientes frente à demanda" (LOMBARDI, 2014, p. 218).

Os esforços despendidos desde 1994 para levar ações educativas relacionadas à prevenção das DST e da AIDS para as escolas tiveram, ainda assim, resultados positivos, se forem levadas em conta as informaçôes aportadas pela Pesquisa Nacional de Saúde do Escolar de 2012 (IBGE, 2013), que objetivou conhecer e dimensionar fatores de risco e de proteçáo à saúde dos estudantes do $9^{\circ}$ ano do ensino fundamental (13 a 15 anos) de escolas públicas e privadas. Em relação ao tema da saúde sexual e reprodutiva, investigou-se: a iniciação sexual, o uso de preservativos e o acesso a informaçôes sobre sexualidade na escola.

Entre as informações obtidas, verificou-se que a iniciação sexual dos jovens brasileiros é precoce: $40,1 \%$ dos meninos e $18,3 \%$ das meninas de 13 a 15 anos já tinham feito sexo (nos municípios das capitais, essas proporçôes eram um pouco mais elevadas). Com relaçáo ao uso do preservativo, $77,1 \%$ dos rapazes e $71,8 \%$ das moças tinham usado na última relação sexual (a proporção era um pouco menor nas capitais). Em relação à educação sexual e reprodutiva recebida na escola, 89,1\% dos estudantes, considerando o país como um todo, e $87,4 \%$ daqueles que viviam em municípios das capitais tinham recebido orientaçáo sobre AIDS e outras DST na escola; no total, $69,7 \%$ dos estudantes e $67,9 \%$ dos residentes em municípios das capitais tinham recebido orientação na escola sobre a aquisição gratuita de preservativo. No primeiro caso (orientação sobre DST e AIDS), as proporçóes variaram muito pouco entre as diferentes regiôes; em relaçáo à orientação sobre preservativo, as taxas foram bem maiores do que a média nacional no Sul e no Centro-Oeste e um pouco menores no Norte e no Sudeste (IBGE, 2013). 
No Censo Escolar de 2013, 93,9\% das escolas urbanas informaram trabalhar com temas de educação em saúde. No entanto, em 90,8\% das escolas federais e em $83,9 \%$ das escolas estaduais, esses temas vinham sendo trabalhados sob a forma de palestras oferecidas aos estudantes, isto é, por meio de açóes pontuais, com frequência semestral e/ou anual, e não de forma contínua e permanente (INEP, 2013).

Esses e outros dados oficiais caracterizam o problema da baixa efetividade de educação em sexualidade no país, que não protege adolescentes e jovens de riscos a sua saúde sexual e reprodutiva: a incidência de gravidez na adolescência permanece elevada e os adolescentes e jovens constituem, hoje, um dos principais grupos de risco para a infecção pelo HIV. No período de 2005 a 2011, o número de mães de 10 a 14 anos de idade aumentou e o de máes do grupo etário de 15 a 19 anos diminuiu. De qualquer forma, as taxas se mantêm elevadas e o grupo mais vulnerável se comporta na direção inversa ao esperado (NEVES; GOMES, 2014). Segundo estudos de vigilância sentinela realizados pela Coordenação Nacional do Programa de Controle das DST e da AIDS, a prevalência de infecção pelo HIV entre conscritos do exército (17 a 21 anos de idade) passou de 0,09\%, em 2002, para $0,12 \%$, em 2007 , indicando um crescimento importante do risco de infecção entre jovens. Nessa faixa de idade, o aumento mais significativo ocorreu entre gays, grupo no qual a taxa variou, no período de 2000 a 2007 , de 0,56 a $1,20 \%$ (SZWARCWALD et al., 2011).

\section{A opinião de stakeholders}

Coordenadores de programas federais, estaduais e municipais de controle das DST e da AIDS e outros stakeholders (ONGs e outras da sociedade civil, de pacientes, de pessoas vivendo com HIV/AIDS, de prostitutas, do movimento gay), quando questionados sobre os projetos (SPE e PSE) e seu desempenho, não têm, em geral, uma avaliação muito positiva sobre a intervenção promovida nas escolas para a prevenção das DST e da AIDS entre adolescentes e jovens.

Mesmo nas redes de escolas que obtiveram melhor desempenho, resultados e sustentabilidade, as ações desenvolvidas conviveram com níveis variáveis de execução e cobertura, na dependência da disponibilidade de recursos e de apoio político-institucional, inclusive com períodos de descontinuidade. Em geral, os gestores entrevistados não dispóem de informações de cobertura.

A absorção do SPE pelo PSE é vista como prejuízo para o alcance dos objetivos de promoção da saúde sexual e reprodutiva e de prevenção das DST e AIDS, em razão da ampliaçáo dos objetivos da intervençáo e da perda de prioridade para a prevenção das DST e da AIDS no novo contexto. Apesar disso, alguns entrevistados entendem que a criação do PSE favoreceu a institucionalização das açóes de prevenção das DST e da AIDS nas Secretarias de Educação e deu mais força à integração interinstitucional de tal forma que gestores da educação e pro- 
fessores se sentem mais responsabilizados com a atividade. A maioria deles, no entanto, relatou que a execução do PSE se caracterizou por grande rotatividade das equipes técnicas estaduais e municipais responsáveis pela gestão do programa e por falta de recursos e de autonomia. Vários entrevistados mencionam o fato de a açáo ser muito dependente de pessoas, em decorrência da falta de prioridade e de apoio institucional por parte das secretarias de educação e dos gestores de escolas.

A integração entre os setores da saúde e da educação é percebida pelos entrevistados como "difícil", e a coordenação interinstitucional, como "complicada". É frequente o emprego de expressões como: "a gente [referindo-se aos técnicos do setor saúde] não consegue entrar na educação"; "existe grande dificuldade para atuar nas escolas"; "o diálogo é difícil"; "a articulação entre saúde e educação efetivamente não acontece". Ainda que mais frequentes por parte do pessoal da saúde, as alegações de dificuldade de interlocução e interação provêm de ambas as partes. Em apenas dois casos, a integração interinstitucional foi avaliada como "boa" tanto no nível central quanto local, sendo reconhecida, no entanto, a sua dependência de condiçóes conjunturais, mais do que estruturais. Cabendo ao setor saúde a liderança do processo de intersetorialidade. Todos os entrevistados se referem à dificuldade de envolver as Secretarias de Educação no processo. Eram sempre as Secretarias de Saúde que alavancavam e financiavam as açóes, enquanto o envolvimento das Secretarias de Educação, sempre referido como muito difícil, dependia excessivamente de condiçóes locais.

As tentativas das pessoas entrevistadas de entender e explicar essas dificuldades apontam para argumentos como: as perspectivas institucionais diferentes em relação à questão (enquanto o setor de saúde tem "uma visão imediatista", voltada para a necessidade de controle da epidemia, o setor de educação percebe a questáo sob a perspectiva da formaçáo integral do adolescente e, portanto, com resultados em longo prazo); a falta de prioridade política conferida à ação pelo Ministério da Educação; o preconceito contra a temática entre gestores e professores; a prevalência elevada, no ambiente e nas comunidades escolares, de "mentalidades arcaicas, de preconceito e de estigma" e de "pensamento tradicional"; professores e trabalhadores de saúde despreparados para a ação educativa em DST/AIDS.

Assim, vários gestores e stakeholders entrevistados reconhecem uma grande dificuldade para atuar nas escolas em razão de resistências tanto pessoais quanto institucionais por parte de gestores, diretores, professores e pais - o que torna a coordenação interinstitucional complicada e a obtenção de níveis de execução de açóes muito variada, na dependência da disponibilidade de recursos, de pessoas e de apoio político-institucional, isto é, de condiçóes conjunturais que se alteram continuamente. De um espaço institucional que se pensava estratégico, a escola transformou-se em "uma barreira quase intransponível ao jovem".

Ademais, observou-se, nos últimos anos, o recrudescimento, no ambiente político, de posiçôes contrárias à diversidade sexual e aos grupos de risco, 
com reflexo sobre as atividades realizadas nas escolas. No Brasil, nos últimos anos, o tema da "Educação em Sexualidade e Gênero" tornou-se um debate público, principalmente político-partidário. Partidos e políticos têm se manifestado sobre a inclusão ou não de temas com esses conteúdos nas escolas de educação básica. A interferência do forte lobby das igrejas cristãs (católica e evangélica), feito por meios de pouca transparência, tanto junto às instâncias decisórias da política quanto às de gestão e execução da atividade, é apontada como um "impedimento sério" à continuidade, à ampliação e à qualidade das açoóes de prevenção das DST e da AIDS nas escolas.

Nesse contexto, alguns materiais e conteúdos produzidos pelos Ministérios da Educação e da Saúde em parceria com organismos internacionais e a sociedade civil organizada tiveram sua distribuição vetada. $\mathrm{O}$ embargo a materiais educativos produzidos no âmbito dos programas foi apontado por vários entrevistados como exemplo da influência nefasta daquele lobby, resultando em comprometimento da qualidade da ação educativa e em desperdício de recursos públicos. Também peças de comunicação social produzidas por organizaçóes parceiras, inclusive ONGs, passaram a ter de ser previamente aprovadas pelas secretarias de saúde - "um nível de censura que jamais existiu no âmbito do Programa de AIDS”.

Essas questôes ideológicas — que ganharam visibilidade com o embargo aos materiais educativos produzidos no âmbito dos projetos - não eram novidade para os gestores e parceiros executores do programa de controle de DST e AIDS, mas seu tratamento conservador se reforçou nos últimos anos, revelando a persistência e a força do preconceito e da discriminação na sociedade brasileira, o que "tornou o ambiente mais complicado do que jamais foi".

$\mathrm{Na}$ opinião dos entrevistados, a prevenção das DST e da AIDS nas escolas contou, inicialmente, com materiais educativos de boa qualidade desenvolvidos durante a vigência do SPE — contrastando com a ausência atual — e vários programas estaduais e municipais produziram materiais próprios. Todos apontam, no entanto, frequentes problemas de distribuição, em decorrência do desconhecimento dos materiais pelas coordenaçóes estaduais, regionais e locais de saúde e de educação, de problemas de logística, de inoperância e de desídia. Vários entrevistados citaram o fato de que os materiais ficavam retidos nas coordenaçóes e não chegavam até as escolas, agravando o problema de carência desses insumos.

A disponibilização de preservativos nas escolas tem sido pouco implementada, segundo as pessoas entrevistadas, apesar do aporte regular, tempestivo e em quantidades adequadas do insumo por parte do Ministério da Saúde e das Secretarias de Saúde. Nos programas que adotaram a disponibilização nas escolas por meio de dispensadores, de "salas de prevençáo", da educação por pares ou outros meios -, ela aconteceu em uma pequena proporção de unidades escolares e sofreu descontinuidade. Alguns programas optaram por disponibilizar os preservativos em serviços de saúde, como estratégia para aproximar os jovens dos servi- 
ços. Essa estratégia, no entanto, é criticada em razão de os serviços de saúde ainda anteporem barreiras ao acesso ao preservativo, em especial para os adolescentes e jovens, por meio de horários limitados de atendimento, exigências de registro ou abertura de prontuário para a dispensação, regulação da quantidade de unidades dispensadas e serviços de segurança e triagem constrangedores.

Enquanto alguns entrevistados relatam a existência de resistência de pais e da comunidade escolar à disponibilizaçáo de preservativos nas escolas, outros relatam a boa aceitação. A receptividade positiva por parte dos adolescentes e jovens é referida por todos os entrevistados. De qualquer forma, nenhum dos entrevistados soube informar dados de cobertura relativos à dispensaçâo de preservativos nas escolas ou fazer um diagnóstico acurado da situação no momento atual.

A sustentabilidade das açóes de prevenção nas escolas é vista com ressalvas por parte dos entrevistados. Para eles, o PSE só tem sustentabilidade porque é mantido pelo Ministério da Saúde, sendo raras as Secretarias de Educação de Estados e municípios que aportam recursos próprios ao financiamento das açóes. A baixa prioridade conferida ao programa por parte do Ministério da Educação, a grande rotatividade das equipes de coordenação em todos os níveis de gestão, a perda de apoio político-institucional com as mudanças de administração nos níveis estaduais e municipais e a insuficiência dos sistemas de informação, que dificultam o acompanhamento e a avaliação da atividade, comprometem a sustentabilidade desses projetos.

O abandono de "um processo compartilhado de decisão e gestão" que originalmente envolvia, além das representaçóes das instituições de educação e saúde, agências da Organização das Nações Unidas (ONU), organizações de trabalhadores da educação e ONGs e OSCs parceiras - e a adoção de uma "abordagem tecnocrática" para a formulação e condução da política e a coordenação das açóes são apontados como "um retrocesso" e como fatores que podem vir a comprometer a qualidade das açóes e a sustentabilidade da atividade.

As ações de treinamento que acompanharam a implantação do SPE, registradas nos relatórios de progresso, foram muito valorizadas pelos entrevistados, que se ressentiram pela sua descontinuidade.

O papel desempenhado pela UNESCO é reconhecido como "estratégico e essencial" para promover a aproximação de interesses e a articulação e cooperação entre os Ministérios da Saúde e da Educação, movimento que resultou na criação e implantação do SPE e do PSE. A cooperação da UNESCO também foi vista como "decisiva" para a elaboração das diretrizes dos projetos, a produção de materiais educativos, a preparação de gestores das Secretarias Estaduais e Municipais de Educaçáo e a constituição dos grupos gestores.

Não há concordância entre os entrevistados quanto ao futuro da atuação nas escolas em relação à prevenção das DST e da AIDS: enquanto a maioria 
entende que, em razáo da importância estratégica de reverter o crescimento da epidemia entre jovens, a ação deverá ser repensada e retomada - de forma isolada ou associada a estratégias complementares —, existem aqueles que defendem que, pela mesma razão, ela deve ser substituída, por ter falhado e por ter a escola se transformado em uma barreira muito difícil de transpor, prejudicando $\mathrm{o}$ acesso aos jovens.

Por outro lado, a busca da instituição por alternativas para levar açóes de prevenção até os jovens é justificada pelo fato de que esse acesso ficou "preso à escola".

De qualquer forma, "esse é um dos principais problemas [não resolvidos] da política”.

\section{Conclusões}

Ações de prevenção das DST e da AIDS dirigidas a adolescentes e jovens escolarizados se executam nas escolas brasileiras desde os primeiros anos da epidemia. Uma política de abrangência nacional, capitaneada pelos Ministérios da Educaçáo e da Saúde, no entanto, só foi formulada em 1994, resultando na proposiçáo e implementação de um conjunto de iniciativas que se sucederam desde então: Projeto Escola (1995-2004); SPE (2005-2007); PSE (de 2007 até o momento).

Inicialmente com foco na prevenção das DST e da AIDS, as ações desenvolvidas nas escolas passaram, com o SPE, a ser contextualizadas na promoção da saúde sexual e reprodutiva e, com a implementaçáo do PSE, a partir de 2007, a integrar um conjunto bem mais amplo de objetivos e conteúdos de saúde, de caráter tanto educativo-preventivo como assistencial. De qualquer forma, a ação teve, desde o início, níveis variáveis de execução, cobertura e qualidade, na dependência da disponibilidade de recursos e de apoio político-institucional, com períodos de descontinuidade.

A absorção do SPE pelo PSE é vista como prejuízo para o alcance dos objetivos de promoção da saúde sexual e reprodutiva e de prevenção das DST e AIDS, em razão da ampliação dos objetivos da intervenção - e consequente dispersão daqueles objetivos específicos - e da perda de prioridade para a prevenção das DST e da AIDS no novo contexto.

Resistências, tanto pessoais quanto institucionais, por parte de gestores, diretores, professores e pais, tornam a coordenaçáo interinstitucional complicada e a obtenção de níveis de execução de açôes muito variada, na dependência de condiçóes conjunturais que se alteram continuamente. De qualquer forma, as Secretarias de Saúde - com recursos federais - têm alavancado e financiado essas açóes, enquanto o envolvimento das Secretarias de Educação depende muito de condiçôes locais. 
A boa qualidade dos materiais educativos desenvolvidos durante a vigência do SPE, inclusive de materiais próprios desenvolvidos por programas estaduais e municipais, contrasta com a ausência atual. Frequentes problemas de distribuição desses materiais agravaram a carência quase generalizada desses insumos.

A disponibilização de preservativos nas escolas, um dos componentes mais estratégicos da política, foi pouco implementada, apesar da oferta regular e em quantidades adequadas desse insumo por parte do Ministério da Saúde e das Secretarias de Saúde. A razão apontada é a resistência de pais e, principalmente, das comunidades escolares. Não foi possível obter dados de cobertura relativos à dispensação de preservativos nas escolas ou fazer um diagnóstico acurado da situação no momento atual.

O recrudescimento, no ambiente político, de posições contrárias à diversidade sexual e aos grupos de risco para a infecção pelo HIV teve reflexo sobre as atividades realizadas nas escolas. A temática tornou-se tema de um debate público, com partidos e políticos se manifestando sobre a inclusão ou não do tema nas escolas de educação básica. Ao mesmo tempo, a interferência do forte lobby das igrejas cristãs (católica e evangélica), tanto junto às instâncias decisórias da política quanto às de gestão e execução da atividade, é apontada como um impedimento sério à continuidade, à ampliação e à qualidade das ações de prevenção das DST e da AIDS nas escolas.

De um espaço institucional que se pensava estratégico, a escola transformou-se em uma barreira quase intransponível ao jovem.

A sustentabilidade das ações de prevenção nas escolas é vista com ressalvas, comprometida por fatores como a baixa prioridade conferida a elas por parte do Ministério da Educação, a grande rotatividade das equipes de coordenação em todos os níveis de gestão, a perda de apoio político-institucional e recursos, e a insuficiência dos sistemas de informação, que dificultam o acompanhamento e a avaliação da atividade.

O papel desempenhado pela UNESCO é reconhecido como estratégico e essencial para promover a aproximação de interesses, a articulação e a cooperação entre os Ministérios da Saúde e da Educação — o que resultou na criação e implantação do SPE e do PSE - e para a elaboração das diretrizes dos projetos, a produção de materiais educativos, a preparaçáo de gestores das Secretarias Estaduais e Municipais de Educação e a constituição dos grupos gestores.

Ainda que informaçôes oficiais apontem, em geral, para o grande número de escolas que trabalham o tema da educação sexual e reprodutiva com foco na prevenção das DST e da AIDS, as avaliações disponíveis mostram, também, baixa efetividade da ação educativa de tal forma, que os jovens constituem, atualmente, uma das populaçóes-chave para o controle da epidemia. 
O futuro da atuação nas escolas com vistas à prevenção das DST e da AIDS é contencioso: enquanto a maioria dos gestores e stakeholders entende que, em razão da importância estratégica de reverter o crescimento da epidemia entre jovens, a ação deverá ser repensada e retomada — de forma isolada ou associada a estratégias complementares -, existem aqueles que defendem que, pela mesma razão, ela deve ser substituída, por ter falhado e por ter a escola se transformado em uma barreira muito difícil de transpor, prejudicando os jovens.

\section{Referências}

BRASIL. Decreto no 6.286, de 5 de dezembro de 2007. Institui o Programa Saúde na Escola - PSE, e dá outras providências. Diário Oficial da União, Brasília, 6 dez. 2007. Disponível em: <http://www.planalto.gov.br/ccivil 03/ Ato2007-2010/2007/Decreto/ D6286.htm>. Acesso em: 24 ago. 2015.

. Ministério da Saúde. Secretaria de Vigilância em Saúde. Programa Nacional de DST e Aids. Diretrizes para implantação do Projeto Saúde e Prevenção nas Escolas. Brasília: Ministério da Saúde, 2006a.

. ORGANIZAÇÃO DAS NAÇÓES UNIDAS PARA A EDUCAÇÃO, A CIÊNCIA E A CULTURA - UNESCO. Ministério da Saúde. Apoio à redução da incidência do HIV/Aids e outras DST e melhoria da qualidade de vida de pessoas vivendo com HIV/Aids no Brasil. Relatório de Progresso 2005, Brasília, nov. 2006b.

. Ministério da Saúde. Apoio à redução da incidência do HIV/Aids e outras DST e melhoria da qualidade de vida de pessoas vivendo com HIV/Aids no Brasil. Relatório de Progresso 2007, Brasília, jun. 2008.

GRANGEIRO, A.; ESCUDER, M.M.L.; SILVA, S.R.; CERVANTES, V.; TEIXEIRA, P.R. Características da resposta à Aids de secretarias de Saúde, no contexto da Política de Incentivo do Ministério da Saúde. Saúde e Sociedade, São Paulo, v. 21, n. 4, p. 954-975, 2012.

INSTITUTO BRASILEIRO DE GEOGRAFIA E ESTATÍSTICA (IBGE). Pesquisa Nacional de Saúde do Escolar 2012. Rio de Janeiro: IBGE, 2013. Disponível em: <http:// biblioteca.ibge.gov.br/visualizacao/livros/liv64436.pdf>. Acesso em: 11 nov. 2014.

INSTITUTO NACIONAL DE ESTUDOS E PESQUISAS EDUCACIONAIS ANÍSIO TEIXEIRA (INEP). Censo Escolar da Educação Básica 2013. Brasília: MEC/INEP, 2013. Disponível em: <http://portal.inep.gov.br/basica-censo >. Acesso em: 20 jul. 2014.

LOMBARDI, C.A. Relatório final da avaliação, com artigo de proposição de cenários para o aprimoramento da política pública de educação em sexualidade, mapeamento de boas práticas nacionais e internacionais. Brasília: UNESCO, mar. 2014.

NEVES, M.B.A.S.; GOMES, C.A. Gravidez adolescente e juvenil: declínio ou estagnação? Revista Brasileira de Sexualidade Humana, Rio de Janeiro, v. 24, n. 2, p. 135-141, dez. 2014. 
ORGANIZAÇÃO DAS NAÇÓES UNIDAS PARA A EDUCAÇÃO, A CIÊNCIA E A CULTURA - UNESCO. Projeto de apoio à redução da incidência do HIVIAids e outras DST e melhoria da qualidade de vida das pessoas com HIVIAids no Brasil: Cooperação Técnica entre o Ministério da Saúde e a UNESCO. Brasília: UNESCO, nov. 2003.

Respuesta de la UNESCO al VIH y el SIDA. Paris: UNESCO, s.d. Disponível em: shttp://www.unesco.org/new/es/unesco/themes/hiv-and-aids/>. Acesso em: 19 set. 2013. RUA, M.G.; ABRAMOVAY, M. Avaliação das açôes de prevenção às DST/Aids e uso indevido de drogas nas escolas de ensino fundamental e médio em capitais brasileiras. Brasília: UNESCO; Brasil Telecom; Fundação Kellogg; Banco Interamericano de Desenvolvimento, 2001.

SOUZA, M.M. Aids - nas escolas prevenção ainda é falha. O Estado de São Paulo, 18 mar. 2004. Caderno Geral Educação, Pagina A12. Disponível em: <http://acervo.estadao.com. br/pagina/\#!/20040318-40329-nac-12-ger-a12-not>. Acesso em: 24 ago. 2015.

STERN, E. The evaluation of UNESCO Brazil's contribution to the Brazilian Aids Programme: final report. (BR/2005/PI/H/19). Brasília: UNESCO, jul. 2005.

SZWARCWALD, C.L.; ANDRADE, C.L.T.; PASCOM, A.R.P.; PEREIRA, G.F.M.; PENHA, I.T. HIV-related risky practices among Brazilian young men, 2007. Cadernos de Saúde Pública, Rio de Janeiro, v. 27, supl. 1, p. S19-S26, 2011.

Recebido em 10 de julho de 2016.

Aceito em 08 de dezembro de 2016. 